[Agr. Biol. Chem., Vol. 34, No. 8, p. 1129 1135, 1970]

\title{
Studies on the Accumulation of Orotic Acid by Escherichia coli $\mathrm{K} 12$
}

\author{
Part II. ${ }^{\dagger}$ Mechanism of the Accumulation ${ }^{\dagger \dagger}$ \\ By Haruhiko Machida, Akira KuninaKa and Hiroshi Yoshino \\ Research Laboratory, Yamasa Shoyu Co., Ltd., Choshi, Japan \\ Received November 24, 1969
}

\begin{abstract}
The mechanism whereby Escherichia coli $\mathrm{K} 12$ accumulates orotic acid in culture fluid was studied. Pyrimidine compounds were incorporated effectively into cells of $E$. coli K12, stimulated the growth, and depressed the accumulation; while purine compounds were not so much consumed by the microorganism for its growth, and affected the accumulation to a lesser extent. On the other hand, E. coli B unable to accumulate orotic acid utilized less effectively pyrimidine compounds for its growth than strain K12.

It is supposed, therefore, that in the de novo pathway for pyrimidine synthesis in $E$. coli $\mathrm{K} 12$ the step from orotic acid to $5^{\prime}$-UMP is genetically depressed so that orotic acid is accumulated when pyrimidine compounds, that would cause a feedback inhibition of orotic acid synthesis upon incorporation, are not supplemented.
\end{abstract}

Orotic acid is excreted in culture fluids of pyrimidine-requiring mutants of Neurospora crassa, $^{21}$ Aerobacter aerogenes ${ }^{31}$ and Escherichia coli. ${ }^{4)}$ The excretion of orotic acid is considered to be caused by a genetic block in the de novo pathway for pyrimidine synthesis especially in the step of decarboxylation of orotidylic acid. $^{5}$ Orotic acid is also accumulated in culture fluid of $E$. coli when the growth is

$t$ The previous paper" is the Part I of the series of "Studies on the Accumulation of Orotic Acid by Escherichia coli K12."

t1 This paper was presented at the Annual Meeting of the Agricultural Chemical Society of Japan, held at Meiji University, Tokyo, on April 1st, 1969.

1) H. Machida and A. Kuninaka, Agr. Biol. Chem., 33, 868 (1969).

2) H. K. Mitchell, M. B. Houlahan and J.F. Nyc, J. Biol. Chem., 172, 525 (1948).

3) D. Ushiba and B. Magasanik, Proc. Soc. Exptl. Biol. Med., 80, 626 (1952); M.S. Brooke, D. Ushiba and B. Magasanik, J. Bacteriol., 68, 534 (1954).

4) R. A. Yates and A. B. Pardee, J. Biol. Chem., 221, 743 (1956).

5) I. Lieberman, A. Kormberg and E. S. Simms, ibid., 215, 403 (1955). inhibited by analogues of pyrimidine such as $6-$ azauracil. ${ }^{6,7)}$ The accumulation can be explained by the competitive inhibition of orotidylic acid decarboxylase by ribonucleotide of the unnatural analogue..$^{8 \sim 101}$ Nakayama et al. ${ }^{111}$ reported that an amino acid-requiring strain of $E$. coli accumulated orotic acid in the presence of $1 \%$ of yeast extract.

In the previous paper, ${ }^{11}$ the authors showed that a wild type strain of E. coli, strain K12, accumulated orotic acid in casamino acids-

6) J. Skoda and F. Sorm, Biochim. Biophys. Acta, 28, 659 (1958); idem, Coll. Czeck. Chem. Commun., 24, 1331 (1959).

7) R. E. Handschumacher, Nature, 182, 1090 (1958).

8) R.E. Handschumacher and C. A. Pasternak, Biochim. Biophys. Acta, 30, 451, (1958); C. A. Pasternak, and R. E. Handschumacher, J. Biol. Chem., 234, 2992 (1959).

9) R. E. Handschumacher, J. Biol. Chem., 235, 2917 (1960).

10) D. A. Smith and D. W. Visser, J. Biol. Chem., 240, 446 (1965).

11) K. Nakayama, Z. Sato, H. Tanaka and S. Kinoshita, Nippon Nogeikagaku Kaishi, 39, 118 (1965). 
glucose medium, while $E$. coli strains other than K12 did not accumulate orotic acid even in a trace amount. The accumulation was concluded to be due to a genetically stabilized property specific to $E$. coli $\mathrm{K} 12$.

In the present paper the mechanism whereby orotic acid is accumulated in the culture fluid of $E$. coli $\mathrm{K} 12$ was studied. From the facts that growth of $E$. coli $\mathrm{K} 12$ was much more stimulated by pyrimidine compounds than by purine compounds, and that the accumulation was completely depressed by supplementation of pyrimidine compounds, orotic acid was supposed to be accumulated on account of a genetical depression in the step from orotic acid to $5^{\prime}$-UMP in the wild type strain. It is interesting that one of the most popular strains of $E$. coli has the above unique genetic property.

\section{MATERIALS AND METHODS}

Microorganisms. E. coli $\mathrm{K} 12 \mathrm{CR} 63$ and E. coli B were employed as a strain which accumulates orotic acid and a strain which does not, respectively. Both strains of $E$. coli were kindly provided by Dr. J. M. Buchanan, Massachusetts Institute of Technology.

Media and bacterial growth. The basal medium consisted of $\mathrm{Na}_{2} \mathrm{HPO}_{4}, \mathrm{I} O_{0}^{\prime} ; \mathrm{KH}_{2} \mathrm{PO}_{4}, 0.5 \% ; \mathrm{MgSO}_{4}$. $7 \mathrm{H}_{2} \mathrm{O}, 0.1 \% ; \mathrm{NH}_{4} \mathrm{Cl}, 0.1 \%$; glucose, $3 \%$; and casamino acids, $2.5 \%$ (hereafter referred to as casamino acids medium). In some cases casamino acids were replaced by $1.25 \%$ of ammonium sulfate (hereafter referred to as ammonium sulfate medium). The bacterial strains were grown as described in the previous paper." Cells were centrifuged down from one volume of the culture fluid and were resuspended in 25 volumes of water. The turbidity of the suspension was then measured at $650 \mathrm{~m} \mu$.

Estimation of the amounts of orotic acid and purine and pyrimidine compounds. The amounts of orotic acid, and purine and pyrimidine compounds in culture fluid were estimated by the two dimensional paper chromatography followed by reading the optical densities of the extracts of the spots as described in the previous paper.1"
Chemicals. Casamino acids were purchased from Difco Laboratories, and yeast extract from Wako Pure Chemical Industries. Nucleosides and nucleotides were prepared from yeast RNA in this laboratory. Uracil and cytosine were purchased from Tokyo Kasei Kogyo Co., Ltd., orotic acid from Kyowa Hakko Kogyo Co., Ltd., and various amino acids from both Nippon Rikagaku Yakuhin Co., Ltd. and Daiichi Pure Chemicals Co., Ltd. Inosine- $8-14 \mathrm{C}$ and uridine-2-214 $\mathrm{C}$ were purchased from Daiichi Pure Chemicals Co., Ltd.

\section{RESULTS}

Effect of amino acids on the accumulation of orotic acid

As shown in Table I, L-aspartic acid, Lthreonine, L-histidine and L-cysteine were found to be effective for the accumulation of orotic acid by $E$. coli $\mathrm{K} 12$ but other amino acids tested were not significantly effective. These amino acids effective for the accumulation of orotic acid were not related with the

TABLE I. EFFect of Amino Acids on THE ACCUMULATION OF OROTIC ACID AND BACTERIAL GROWTH

E. coli $\mathrm{K} 12$ was grown in an ammonium sulfate medium containing $1 \mathrm{mM}$ of L-amino acid indicated in the table.

\begin{tabular}{|c|c|c|c|c|}
\hline \multirow{2}{*}{$\begin{array}{l}\text { Amino } \\
\text { acid added }\end{array}$} & \multicolumn{2}{|c|}{$\begin{array}{c}\text { Growth } \\
(\text { O. D. at } 650 \mathrm{~m} \mu)\end{array}$} & \multicolumn{2}{|c|}{$\begin{array}{l}\text { Orotic acid } \\
\text { (mg/liter) }\end{array}$} \\
\hline & $8 \mathrm{hr}^{a}$ & 24hr & $24 \mathrm{hr}$ & $48 \mathrm{hr}$ \\
\hline None (control) & 0.180 & 0.167 & 83 & 113 \\
\hline Alanine & 0.175 & 0.164 & 88 & 118 \\
\hline Aspartic acid & 0.190 & 0.175 & 90 & 143 \\
\hline Glutamic acid & 0.188 & 0.170 & 91 & 120 \\
\hline Glutamine & 0.189 & 0.175 & 82 & 119 \\
\hline Lysine & 0.185 & 0.178 & 99 & 109 \\
\hline Threonine & 0.192 & 0.175 & 96 & 139 \\
\hline Arginine & 0.190 & 0.175 & 79 & 98 \\
\hline Histidine & 0.169 & 0.175 & 105 & 130 \\
\hline Cysteine & 0.168 & 0.160 & 106 & 170 \\
\hline Tryptophan & 0.189 & 0.175 & 91 & 112 \\
\hline
\end{tabular}

a) Only in this case, cells were resuspended in 5 volumes of water in place of 25 volumes of water. 
intermediates in de novo pathway of pyrimidine biosynthesis.

Effect of purine and pyrimidine compounds on the accumulation of orotic acid and bacterial growth

The presence of a pyrimidine nucleoside $(5 \mathrm{mM})$ markedly stimulated growth of $E$. coli $\mathrm{K} 12$ especially in the early period of culture and completely depressed the accumulation of orotic adid. On the other hand, adenosine and inosine ( $5 \mathrm{mM}$ ) affected the growth a little and depressed the accumulation only in the late period of culture (Fig. 1). As compared with

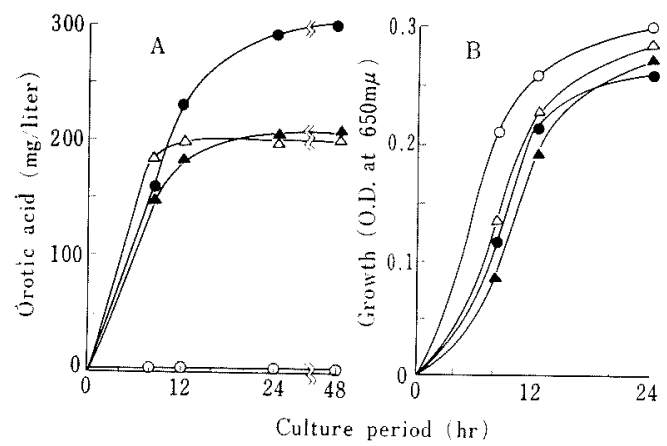

FIG. 1. Effect of Purine and Pyrimidine Nucleosides on the Accumulation of Orotic Acid (A) and Bacterial Growth (B).

E. coli K12 was grown in a casamino acids medium containing $5 \mathrm{mM}$ of nucleoside.

- Control, no nucleoside was added.

$\triangle \longrightarrow$ Inosine. $\Delta-\Delta$ Adenosine.

$\mathrm{O}-\mathrm{O}$ Uridine or cytidine.

adenosine, positive effect of inosine on both he growth and the accumulation in the early Jeriod was observed significantly. Effect of aanthosine and guanosine on the growth was imilar to that of inosine, and effect of the ormer two compounds on the accumulation vas similar to that of adenosine. Relationhip between the amount of uridine or inosine upplemented and the amount of orotic acid sccumulated or the bacterial growth is llustrated in Fig. 2. It is interesting that

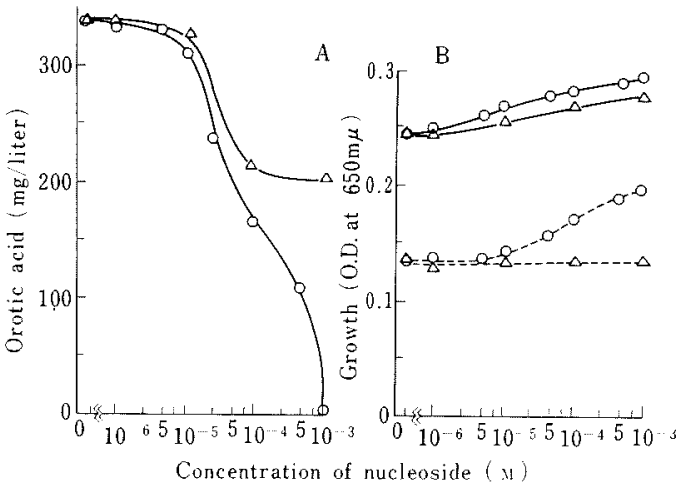

FIG. 2. The Accumulation of Orotic Acid (A) and Bacterial Growth (B) as Functions of Concentration of Uridine or Inosine.

E. coli $\mathrm{Kl} 2$ was grown for $24 \mathrm{hr}$ in casamino acids media containing various concentrations of uridine $(\bigcirc)$ or inosine $(\triangle)$. Broken lines indicate growth at $8 \mathrm{hr}$ 's culture.

both inhibition of the orotic acid accumulation and stimulation of the growth were observed as functions of concentration of uridine. The threshold concentration of uridine as the inhibitor for the accumulation

TABLE II. EFFECT OF PYRIMIDINE COMPOUNDS ON THE ACCUMULATION OF OROTIC ACID AND BACTERIAL GROWTH

\begin{tabular}{|c|c|c|c|c|c|c|}
\hline \multirow{3}{*}{$\begin{array}{l}\text { Pyrimidine } \\
\text { added } \\
(2 \mathrm{~m})\end{array}$} & \multirow{3}{*}{$\begin{array}{r}\text { Growth } \\
\text { (O.D. at } \\
650 \mathrm{~m} \mu) \\
8 \mathrm{hr}\end{array}$} & \multirow{2}{*}{\multicolumn{2}{|c|}{$\begin{array}{c}\text { Orotic acid } \\
\text { accumulated } \\
\text { (mg/liter) }\end{array}$}} & \multicolumn{3}{|c|}{$\begin{array}{l}\text { Pyrimidine } \\
\text { remained (mM) }\end{array}$} \\
\hline & & & & \multicolumn{2}{|c|}{$12 \mathrm{hr}$} & \multirow{2}{*}{$\frac{24 \mathrm{hr}}{\mathrm{Ur}^{a}}$} \\
\hline & & $12 \mathrm{hr}$ & $24 \mathrm{hr}$ & $5^{\prime}-\mathrm{Nt}$ & $\mathrm{Ur}^{a}{ }^{\prime}$ & \\
\hline None & 0.098 & 300 & 306 & 0 & 0 & 0 \\
\hline Uracil & 0.194 & 0 & 0 & 0 & 1.49 & 1.41 \\
\hline Uridine & 0.20 & 0 & 0 & 0 & 1.37 & 1.39 \\
\hline $5^{\prime}-\mathrm{UMP}$ & 0.144 & 118 & 137 & 0.6 & 1.05 & 1.75 \\
\hline Cytosine & 0.196 & 0 & 0 & 0 & 1.32 & 1.31 \\
\hline Cytidine & 0.197 & 0 & 0 & 0 & 1.32 & 1.33 \\
\hline $5^{\prime}-\mathrm{CMP}$ & 0.147 & 105 & 111 & 0.68 & 1.04 & 1.66 \\
\hline
\end{tabular}

a) Each pyrimidine compound added in the media was completely converted to uracil during growth, except $5^{\prime}$-CMP and 5'-UMP which partly remained unchanged after $12 \mathrm{hr}$ 's culture. 
or the stimulator for the growth was about $1 \times 10^{-5} \mathrm{M}$.

Table II is a summary of the effects of pyrimidine compounds on both the growth and the accumulation of orotic acid. Uracil and cytosine, as well as their nucleosides, stimulated the growth and depressed the accumulation of orotic acid. The effects of

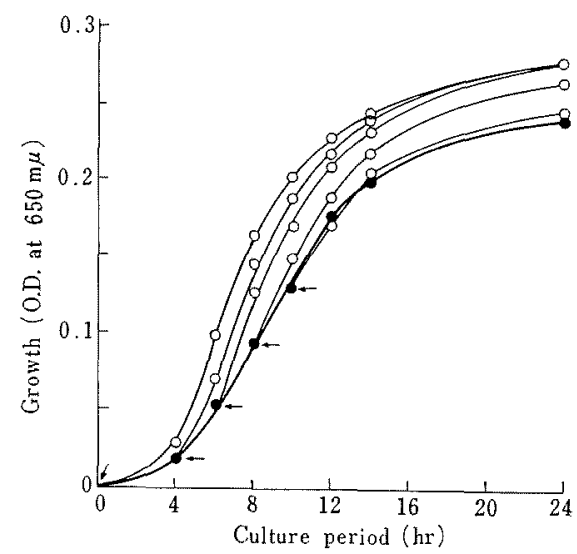

FIG. 3. Stimulation of the Growth of E. coli $\mathrm{K} 12$ by Periodical Addition of $2 \mathrm{~mm}$ Uracil in Casamino Acids Medium.

- Without uracil. $\bigcirc-0$ With uracil. $\longleftarrow$ Time of addition of uracil.

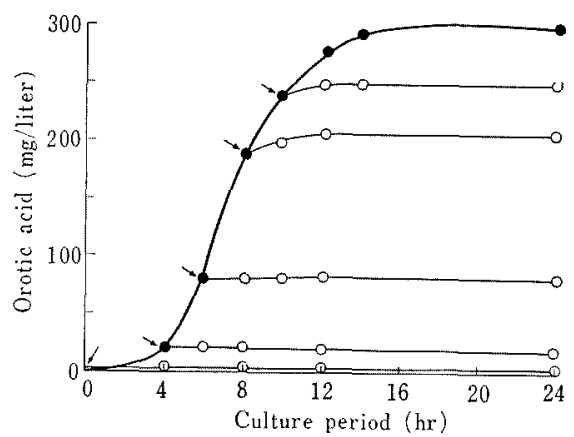

FIG. 4. Inhibition of the Accumulation of Orotic Acid by Periodical Addition of $2 \mathrm{mM}$ Uracil to the Culture of E. coli K12 Grown in Casamino Acids Medium.

- Without uracil. O-O With uracil. $\longleftarrow$ Time of addition of uracil.
$5^{\prime}$-UMP and $5^{\prime}$-CMP, however, were less than those of pyrimidine bases or nucleosides. This result may be related to the less availability of the nucleotides due to their low permeability. Moreover, the effects of the pyrimidine bases and nucleosides on both the growth and the accumulation of orotic acid were clearly observed immediately irrespective of the time of the addition. Typical results are illustrated graphically in Figs. 3 and 4.

Effect of yeast extract on the accumulation of orotic acid and bacterial growth

As described in the previous paper, ${ }^{1 /} E$. coli $\mathrm{K} 12$ failed to accumulate orotic acid when it was grown in a medium containing yeast extract as nitrogen source instead of casamino acids. A proof was obtained that the effect of yeast extract might be able to ascribe to the pyrimidine components: The

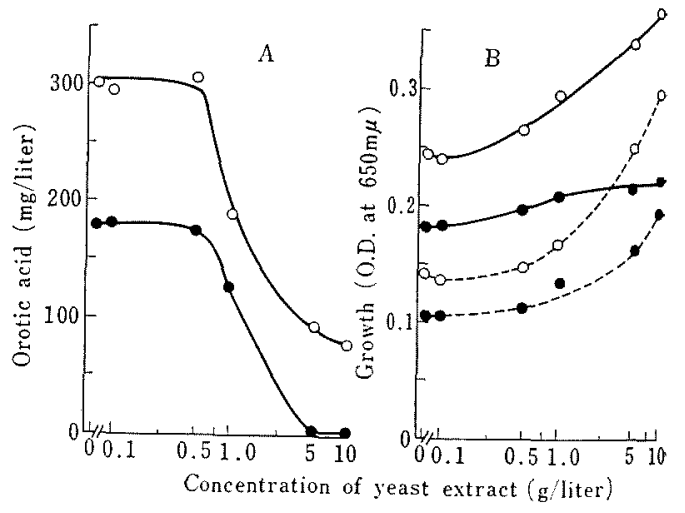

FIG. 5. The Accumulation of Orotic Acid (A) and Bacterial Growth (B) as Functions of Concentration of Yeast Extract.

$E$. coli $\mathrm{Kl} 2$ was grown in media containing various concentrations of yeast extract indicated.

$\mathrm{O}-\mathrm{O}$ Casamino acids medium, $24 \mathrm{hr}$ after inoculation.

-----O Casamino acids medium, $8 \mathrm{hr}$ after inoculation.

- Ammonium sulfate medium, $48 \mathrm{hr}$ after inoculation.

------ Ammonium sulfate medium, $16 \mathrm{hr}$ after inoculation. 
influence of yeast extract shown in Fig. 5 was similar to that of pyrimidine compound discussed earlier. As 1 per cent solution of yeast extract is estimated to contain about 0.8 mmole per liter of pyrimidine compounds (mainly uracil and uridine), ${ }^{12}$ the curves shown in Fig. 5 may be regarded as substantially identical with the curves shown in Fig. 2.

Comparison of E. coli $B$ with E. coli $K 12$

To make clear the specific property of $E$. coli $\mathrm{K} 12$, the strain was compared with $E$. coli B which had been demonstrated to be unable to accumulate orotic acid. The following points were studied; (1) relationship between bacterial growth and addition of nucleosides, (2) incorporation rates of nucleosides, and (3) accumulation and consumption of orotic acid in media during growth.

In the basal media little difference was observed between the growth of $E$. coli $\mathrm{K} 12$ and that of $E$. coli B (Table III). However, effects of purine and pyrimidine compounds on the growth of strain B were clearly distinguished from those on the growth of strain K12. As shown in Table III, the

TABLE III. EFFECT OF URIDINE AND INOSINE ON THE GROWTH OF $E$. coli K12 AND B

\begin{tabular}{|c|c|c|c|c|c|}
\hline \multirow{3}{*}{$\begin{array}{l}\text { Added } \\
\text { material }\end{array}$} & \multirow[t]{2}{*}{ Medium } & \multicolumn{4}{|c|}{ Relative growth } \\
\hline & & \multicolumn{4}{|c|}{$\begin{array}{l}\text { Casamino acids Ammonium sulfate } \\
\text { medium ( } 8 \mathrm{hr}) \quad \text { medium (16hr) }\end{array}$} \\
\hline & 1 Strain & $\mathrm{K} 12$ & B & $\mathrm{K} 12$ & $\mathrm{~B}$ \\
\hline \multirow{2}{*}{\multicolumn{2}{|c|}{ None (control) }} & 1.00 & 1.00 & 1.00 & 1.00 \\
\hline & & $(0.150)$ & $(0.169)$ & $(0.108)$ & $(0.098)$ \\
\hline \multirow[t]{2}{*}{ Uridine } & $0.5 \mathrm{mM}$ & 1.48 & 1.03 & 1.06 & 0.96 \\
\hline & $2.0 \mathrm{~mm}$ & 1.61 & 1.03 & 1.12 & 0.90 \\
\hline \multirow[t]{2}{*}{ Inosine } & $0.5 \mathrm{mM}$ & 1.13 & 1.09 & 1.04 & 1.06 \\
\hline & $2.0 \mathrm{mM}$ & 1.11 & 1.20 & 1.07 & 1.17 \\
\hline
\end{tabular}

Value in the parentheses is optical density at 650 $\mathrm{m} \mu$.

12) A. Kuninaka, unpublished data. growth of strain B was not affected by uridine but stimulated a little by inosine, whereas the growth of strain K12 was markedly stimulated by the former but not so much by the latter.

Figure 6 indicates that strain K12 incorporated a larger amount of uridine than inosine, while strain B incorporated a larger amount of inosine than uridine. This tendency was

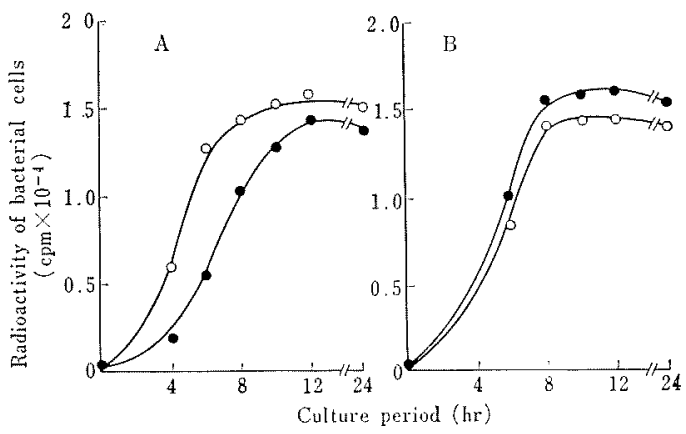

FIG. 6. Incorporation of Uridine-2-14 C and Inosine$8.14 \mathrm{C}$ by $E$. coli $\mathrm{K} 12$ (A) and $E$. coli $\mathrm{B}(\mathrm{B})$.

Both strains were grown in casamino acids medium containing uridine-2-14 $\mathrm{C}(\mathrm{O})$ or inosine-8${ }^{14} \mathrm{C}(\bullet)\left(4.2 \times 10^{4} \mathrm{cpm} / 2 \mu \mathrm{moles} / \mathrm{ml}\right) . \quad 0.5 \mathrm{ml}$ of the culture fluid was centrifuged at $6000 \mathrm{~g}$ for $10 \mathrm{~min}$ and bacterial cells were washed with $2 \mathrm{ml}$ of casamino acids medium. Radio activities of the cells were counted by a gas-flow counter.

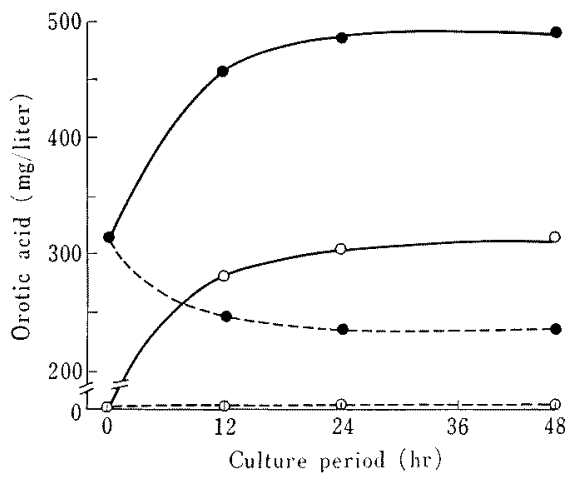

FIG. 7. Accumulation and Consumption of Orotic Acid by $E$, coli K12 and B during Growth.

Strain K12 (solid line) and B (broken line) were grown in casamino acids medium (O), and orotic acid-containing casamino acids medium 
observed clearly during logarithmic phase of the growth. Supplemented orotic acid affected neither the growth of $E$. coli $\mathrm{K} 12$ nor that of $E$. coli B, and, moreover, the compound did not depress further accumulation of orotic acid in strain $\mathrm{K} 12$, while it was consumed by strain $B$ (Fig. 7).

\section{DISGUSSION}

As reported in the previous paper, ${ }^{1 /} E$. coli K12 accumulates orotic acid and the ability is a genetically stabilized property of the strain. In the present experiments it was observed that pyrimidine compounds added exogenously were taken up by the bacterial cells resulting in stimulation of the growth and in depression of the formation of orotic acid. In general, the addition of excess amounts of pyrimidine nucleosides to bacterial cells inhibits de novo synthesis of pyrimidine compound by a feedback mechanism. ${ }^{13,14}$

Orotic acid may be accumulated by $E$. coli $\mathrm{K} 12$ by the following mechanism: The step from orotic acid to $5^{\prime}$-UMP in the de novo pathway for pyrimidine synthesis in E. coli $\mathrm{K} 12$ is naturally depressed. Provided pyrimidine compounds are not supplemented, therefore, the level of pyrimidine nucleotides in the bacterial cells may be too low to cause feedback inhibition. The following observations support the above view: (1) E. coli K12 incorporates a larger amount of pyrimidine compounds than that of purine compounds. This observation suggests that pyrimidine nucleotides are more effective nutrients than purine nucleotides for a rapid growth. Pyrimidine compounds depress the accumulation of orotic acid, and both the stimulation of the bacterial growth and the depression of

13) R. A. Yates and A.B. Pardee, J. Biol. Chem., 221, 757 (1956); J. C. Gerhart and A. B. Pardee, ibid., 237, 891 (1962).

14) P. M. Anderson and A. Meister, Biochemistry, 5, 3164 (1966); P. M. Anderson and S. V. Marvin, Biochem. Biophis. Res. Comm., 32, 928 (1968). the accumulation were observed immediately after the addition of pyrimidine compounds, irrespective of the time of addition. This observation suggests that the sufficient amounts of pyrimidine nucleotides, rapidly formed from exogenous pyrimidine compounds by salvage synthesis, may depress the initial reaction in de novo synthesis of pyrimidine by feedback inhibition. $^{13,141}$ (3) E. coli $\mathrm{Kl} 2$ accumulates orotic acid even when orotic acid is added exogenously, and the supplemented orotic acid does not stimulate the growth. This observation suggests that 5'-UMP may not be formed effectively from orotic acid in the bacterial strain and that in the absence of exogenous pyrimidine compounds, the initial reactions in the pyrimidine pathway may be free from feedback inhibition. Generally, orotidylic acid is not excreted directly from the cells due to the permeability barrier. Therefore, even if orotidylic acid were formed in the bacterial cells excessively, orotic acid would be excreted in place of orotidylic acid, as the equilibrium constant in the reaction of orotidylic acid synthesis from orotic acid was reported to be approximately $0.1 .^{4}$ As this strain can normally grow without supplementation of any pyrimidine compound, it is distinguished from pyrimidine-requiring

Table IV. SUMmary of COMParison of Strain K12 WITH STRAIN B

\begin{tabular}{cccc} 
Strain & Incorporation & $\begin{array}{l}\text { Stimulation } \\
\text { of growth }\end{array}$ & Accumulation \\
\hline KI2 & UrR $>$ HxR & UrR $>\mathrm{H} \times \mathrm{R}$ & Orotic acid \\
B & HxR $>$ UrR & HxR $>$ UrR & $(\text { AICA })^{a}$ \\
\hline
\end{tabular}

a) Accumulation of 5-amino-4-imidazolecarboxamide (AICA) by E. coli B was reported by Stewart et al. ${ }^{15}$ and Shiro. ${ }^{16}$ ) The amount of the accumulated amide was 2 to $3 \mathrm{mg}$ per liter in the former and 10 to $40 \mathrm{mg}$ per liter in the latter.

15) R. C. Steward and M. G. Sevag, Arch. Biochem. Biophys., 41, 9 (1952).

16) T. Shiro, Agr. Biol. Chem., 25, 350 (1961); idem, ibid., 26, 75 (1962). 
mutants, but resembles pyrimidine-leaky and pyrimidine nucleotides. Jacoby and mutants.

Gorini, ${ }^{17}$ noteworthily, reported that control

From the genetical point of view, it is interesting to compare $E$. coli strain $\mathrm{K} 12$ with strain B. As summarized in Table IV, it is apparent that the most typical strains of $E$. coli are genetically distinguished from each other in the activity of synthesis of purine mechanism of arginine pathway in $E$. coli strain $\mathrm{K}$ was genetically distinguished from that in strain $B$.

17) G. A. Jacoby and L. Gorini, J. Mol. Biol., 24, $41(1967)$. 